\title{
KOMPOS PELEPAH KELAPA SAWIT DENGAN BIOAKTIVATOR MOL LIMBAH CAIR PABRIK KELAPA SAWIT UNTUK PERBAIKAN SIFAT KIMIA TANAH LAHAN SUB OPTIMAL
}

\author{
(Oil Palm Midrib Compost with Palm Oil Mill Liquid Bioactivator for Improving Soil Chemical \\ Properties Sub-optimal land)
}

\author{
Zainudin $^{1}$, Tutik Nugrahini ${ }^{1}$, dan Roro Kesumaningwati ${ }^{2}$ \\ ${ }^{1}$ Agrotechnology Study Program Widya Gama Mahakam University \\ ${ }^{2}$ Agroekoteknology Study Program Mulawarman University \\ Jl.K.H Wahid Hasyim Sempaja Samarinda \\ email : zainudin@uwgm.ac.id
}

Article Submitted : 02-01-2020

Article Accepted : 07-02-2020

\begin{abstract}
This research was conducted in April to September 2019 at the Faculty of Agriculture, Widya Gama Mahakam University, Samarinda. The purpose of this study was to determine changes in soil chemical properties of sub-optimal land applied to oil palm midrib compost with mole bioactivator of palm oil mill effluent. The method used in this study was arranged in a Completely Randomized Design (CRD) with Experiment 3 treatment and 6 replications. The first treatment $(\mathrm{P} 1)$ is sub-optimal soil of $10 \mathrm{~kg}+200 \mathrm{~g}$ of palm frond compost which is applied to liquid waste moles. The second treatment (P2) is sub-optimal soil $10 \mathrm{~kg}+400 \mathrm{~g}$ of compost applied to moll liquid waste and the third treatment (P3) is sub optimal soil $10 \mathrm{~kg}+600 \mathrm{~g}$ of compost applied to liquid waste mole. Soil analysis results show that the $\mathrm{pH}$ of the soil has increased from 5.85 to 6.08 , with total nitrogen from 0.20 to 0.58 . Phosphorus has decreased from 70.10 to 5.97 (P1), Potassium has decreased from 182.45 to 32.56 (P1), Cation Exchange Capacity has decreased from 20.16 to 13.10 (P1), and Base Saturation decreased from 73.8 to $37.2(\mathrm{P} 3)$.
\end{abstract}

Keywords: Palm Midrib Compost, POME Bioactivator, Sub-optimal land

\section{PENDAHULUAN}

Lahan sub optimal yang banyak tersebar di Kalimantan dengan pemanfaatan sebagian besar pada aktivitas penambangan batubara, akan meninggalkan lahan bekas tambang yang berpengaruh nyata terhadap penurunan kimia tanah, terutama disebabkan perubahan lapisan tanah dan penurunan kandungan bahan organik. Ditambahkan oleh Mulyani, A., dkk (2016) bahwa lahan suboptimal sebagai lahan potensial untuk pengembangan tanaman pangan, dan tanaman tahunan, sebagian besar pada lahan kering masam, lahan kering iklim kering, lahan rawa pasang surut, dan lahan gambut. Lahan-lahan ini secara biofisik mempunyai berbagai kendala dan faktor pembatas, sehingga perlu dukungan teknologi inovatif peningkatan kesuburan konservasi tanah dan air, varietas unggul baru dan perbenihan yang adaptif pada berbagai subagroekosistem lahan suboptimal. Menurut Haryono dalam Irawan (2015), optimalisasi lahan sub optimal ditempuh melalui dua pendekatan, yaitu: (a) optimalisasi dan (b) ektensifikasi. Pendekatan optimalisasi adalah pemanfaatan 
lahan sub optimal eksisting secara lebih produktif dan lestari melalui intensifikasi yang didukung oleh penerapan inovasi tekonologi.

Limbah perkebunan sangat terdiri dari limbah padat dan limbah cair. Limbah padat salah satunya berupa pelepah kelapa sawit dan limbah cair berupa larutan POME. Limbah pelepah kelapa sawit sangat potensial dimanfaatkan sebagai kompos untuk menyuburkan tanah. Menurut Haji (2013) kandungan pelepah kelapa sawit terdiri dari $24 \%$ hemiselulosa, $40 \%$ selulosa, 21\% lignin, serta komponen lainnya. Komponen yang terdiri dari bahan yang sulit untuk terurai menuntut perlunya ada cara cepat yang dapat mengurai komponen tersebut agar dapat meningkatkan unsur hara tanaman. Pemanfaatan pelepah kelapa sawit sebagai kompos memerlukan bioaktivator untuk mempercepat proses dekomposisi. Limbah cair pabrik kelapa sawit (POME) dapat dimanfaatkan sebagai bioaktivator untuk mempercepat pengomposan. Menurut Nursanti (2013) dalam Madusari, S. (2017), limbah cair pabrik kelapa sawit memiliki potensi untuk dijadikan aktivator karena memiliki aktivitas mikroorganisme yang tinggi.

Pengomposan pelepah kelapa sawit dengan memanfaatkan mol limbah cair pabrik kelapa sawit sebagai dekomposer diharapkan dapat mengefisienkan biaya pembuatan kompos. Penggunaan pupuk organik dengan menggunakan bioaktivator larutan mikroorganisme akan dapat memperbaiki kualitas lahan sub optimal, meliputi peningkatan sifat kimia tanah dan perbaikan sifat biologi tanah.

\section{METODE PENELITIAN}

\section{Rancangan Penelitian}

Penelitian menggunakan Rancangan Acak Lengkap (RAL) dengan percobaan 3 perlakukan 6 ulangan. Perlakuan pertama (P1) yaitu tanah lahan sub optimal $10 \mathrm{~kg}+$ 200g kompos pelepah teraplikasi mol limbah cair. Perlakuan kedua (P2) yaitu tanah lahan sub optimal $10 \mathrm{~kg}+400 \mathrm{~g}$ kompos pelepah teraplikasi mol limbah cair dan Perlakuan ketiga (P3) yaitu tanah lahan sub optimal 10 $\mathrm{kg}+600 \mathrm{~g}$ kompos pelepah teraplikasi mol limbah cair.

\section{Pelaksanaan Penelitian}

Penelitian dilaksanakan berskala laboratorium yang dilakukan di green house kebun percobaan Fakultas Pertanian Universitas Widya Gama Mahakam Samarinda. Penelitian dilakukan mulai bulan April sampai dengan Desember 2019. Pembuatan larutan mikroorganisme POME memerlukan waktu \pm 21 hari, pembuatan kompos pelepah kelapa sawit dengan bioaktivator poin (1) memerlukan waktu sekitar 45 hari, Inkubasi tanah lahan sub optimal dengan masukan kompos selama 30 hari dan analisis sifat kimia tanah hasil inkubasi di laboratorium.

\section{HASIL DAN PEMBAHASAN}

\section{Analisis kompos limbah pelepah kelapa sawit dengan mol POME}

$\begin{array}{cccr}\text { Limbah } & \text { pelepah } & \text { kelapa } & \text { sawit } \\ \text { merupakan } & \text { salah } & \text { satu } & \text { limbah }\end{array}$ pertanian/perkebunan yang menjadi sumber bahan organik yang dapat dimanfaatkan kembali ke tanah. Limbah pelepah kelapa sawit ini sangat berpotensi untuk diolah menjadi bahan yang bermanfaat untuk meningkatkan kesuburan tanah secara alami sebagai pupuk organik, karena mengandung hara yang cukup tinggi. 
Tabel 1. Analisis kompos limbah pelepah kelapa sawit dengan mol POME

\begin{tabular}{|c|c|c|c|c|c|c|}
\hline No & $\mathrm{pH}$ & C org & $\% \quad \mathrm{~N}$ total & $\mathrm{C} / \mathrm{N}$ & $\mathrm{P}_{2} \mathrm{O}_{5}$ & $\begin{array}{l}\mathrm{K}_{2} \mathrm{O} \\
\text { Total }(\%)\end{array}$ \\
\hline 1 & 7,15 & 12,95 & 1,28 & 10,12 & 0,53 & 2,02 \\
\hline
\end{tabular}

Hasil analisis kompos limbah pelepah kelapa sawit dengan mol POME menunjukkan bahwa $\mathrm{pH} \quad 7,15$ sesuai persyaratan teknis minimal pupuk organik no $261 / \mathrm{KPTS} / \mathrm{SR} 310 / \mathrm{M} / 4 / 2019$, C organik $12,95 \%$ tidak sesuai persyaratan teknis minimal pupuk organik, $\mathrm{C} / \mathrm{N} \quad 10,12$ persyaratan teknis minimal pupuk organik, hara makro $\left(\mathrm{N}+\mathrm{P}_{2} \mathrm{O}_{5}\right)$ dengan nilai $3,83 \%$ sesuai persyaratan teknis minimal pupuk organik.

Menurut Hutagalung dan Jalaluddin (1982) dalam Suryanto, T (2018) menyatakan bahwa jumlah pelepah kelapa sawit yang dihasilkan perkebunan kelapa sawit mencapai kurang lebih 2,3 ton/ha bahan kering, bahkan produksi dapat mencapai 40 - 50 pelepah/pohon/tahun dengan berat 4,5 $\mathrm{kg} /$ pelepah. Berdasarkan hasil penelitian Syahfitri (2008) dalam Sinaga (2015), kandungan unsur hara pada pelepah kelapa sawit yaitu sebagai berikut: N 2,6-2,9 (\%); P 0,16-0,19(\%); K 1,1-1,3(\%); Ca 0,5-0,7(\%); $\mathrm{Mg} \quad 0,3-0,45(\%) ; \quad \mathrm{S} \quad 0,25-0,40(\%) ; \quad \mathrm{Cl}$ 0,50,7(\%); B 15-25 ( $\mu \mathrm{g}-1)$; Cu 5-8 ( $\mu \mathrm{g}-1)$ dan Zn 12-18 ( $\mu$ g-1). Pupuk organik disamping dapat mensuplai hara makro, juga dapat menyediakan unsur hara mikro sehingga dapat mencegah kehilangan unsur mikro pada tanah marginal atau tanah yang telah diusahakan secara intensif dengan pemupukan yang kurang seimbang. Semakin tingginya aplikasi pupuk anorganik tanpa pengembalian bahan organik ke tanah mengakibatkan keseimbangan dan ketersediaan hara tanah menjadi terganggu. Pupuk organik merupakan salah satu alternatif untuk meningkatkan ketersediaan, kecukupan, dan efisiensi serapan hara bagi tanaman (Siregar dan Hartatik, 2010).

Selanjutnya Yuwono (2008) dalam Sismiyanti, Hermansah, dan
Yulnafatmawita. (2018) juga memperkuat bahwa $\mathrm{C} / \mathrm{N}$ akan mempengaruhi kualitas bahan organik. Kualitas bahan organik akan menentukan kecepatan mineralisasi residu tanaman yang merupakan faktor yang kritikal dalam mempengaruhi dekomposisi dan pelepasan unsur hara terutama ketika bahan organik tersebut akan diolah menjadi pupuk organik. Berdasarkan kualitasnya bahan organik dibagi menjadi tergolong berkualitas tinggi bila mengandung $\mathrm{N}$ paling sedikit $2,5 \%$. Bila diaplikasikan ke dalam tanah (sebagai pupuk hijau), pelepasan $\mathrm{N}$ benar-benar dapat terjadi (net release of nitrogen) $\mathrm{Di}$ sisi lain, bahan tanaman yang mengandung $\mathrm{N}<2,5 \%$ tergolong berkualitas rendah, maka bahan-bahan tanaman akan menyebabkan terjadinya imobilisasi $\mathrm{N}$ selama proses dekomposisi. Berdasarkan analisis $\mathrm{N}$ pada pelepah kelapa sawit diperoleh bahwa $\mathrm{N}$ sebesar 1,28\% sehingga tergolong rendah, hal ini menyebabkan pelepah kelapa sawit harus dikomposkan terlebih dahulu sebelum aplikasi ke dalam tanah untuk menghindari terjadinya imobilisasi.

Supriyadi (2008) melaporkan bahwa substrat organik dengan rasio $\mathrm{C} / \mathrm{N}$ sempit $(<25)$ menyebabkan dekomposisi berjalan cepat, sebaliknya pada bahan dengan $\mathrm{C} / \mathrm{N}$ lebar (>25) maka mendorong terjadinya immobilisasi. Berdasarkan analisis $\mathrm{C} / \mathrm{N}$ limbah pelepah kelapa sawit diperoleh bahwa $\mathrm{C} / \mathrm{N} 10,12$, hal ini menunjukkan bahwa kisaran $\mathrm{C} / \mathrm{N}$ bahan organik berada pada kondisi sempit yaitu $<20 \%$. bahan organik dalam kondisi segar berarti akan membutuhkan waktu yang lebih singkat dalam proses dekomposisi dan mineralisasi $\mathrm{N}$ dibandingkan dengan lainnya. Pada 
umumnya bahan organik segar memiliki potensi lebih cepat terdekomposisi.

\section{Analisis tanah awal pada lahan sub optimal}

Hasil analisis tanah awal menunjukkan bahwa $\mathrm{pH}$ tanah adalah 5,85 atau tergolong agak masam. Karbon organik $0,85 \%$ tergolong sangat rendah, $\mathrm{N}$ total $0,20 \%$ tergolong rendah, $\mathrm{C} / \mathrm{N} \mathrm{4,33}$ tergolong sangat rendah, $\mathrm{P}$ tersedia 70,10 ppm tergolong sangat tinggi, $\mathrm{K}$ tersedia $182,45 \mathrm{ppm}$ tergolong sangat tinggi, kation basa $\mathrm{Ca} 8,83 \mathrm{Me} / 100 \mathrm{~g}$ tergolong sedang, $\mathrm{Mg} 4,08 \mathrm{Me} / 100 \mathrm{~g}$ tergolong tinggi, K 1,37 $\mathrm{Me} / 100 \mathrm{~g}$ tergolong sangat tinggi, $\mathrm{Na}$ $\mathrm{Me} / 100 \mathrm{~g}$ 0,59 tergolong sedang, KTK $20,16 \mathrm{Me} / 100 \mathrm{~g}$ tergolong sedang, dan kejenuhan basa $73,8 \%$ tergolong tinggi.

Tabel 2. Analisis tanah awal pada lahan sub optimal

\begin{tabular}{|c|c|c|c|c|c|c|c|c|c|c|c|c|}
\hline \multirow[b]{2}{*}{ No } & \multirow[b]{2}{*}{$\mathrm{pH}$} & \multirow{2}{*}{\multicolumn{2}{|c|}{$\begin{array}{c}\text { Corg } \\
\%\end{array}$}} & \multirow[b]{2}{*}{$\mathrm{C} / \mathrm{N}$} & $\mathrm{P}$ & $\mathrm{K}$ & \multicolumn{4}{|c|}{ Kation basa (pH 7) } & \multirow{2}{*}{ KTK } & \multirow[b]{2}{*}{$\begin{array}{c}\text { Kej Basa } \\
(\%)\end{array}$} \\
\hline & & & & & & $\begin{array}{l}\text { edia } \\
\text { m) }\end{array}$ & $\mathrm{Ca}$ & $\mathrm{Mg}$ & $\begin{array}{c}\mathrm{K} \\
\mathrm{Ke} / 100\end{array}$ & $\begin{array}{l}\mathrm{Na} \\
\mathrm{g})\end{array}$ & & \\
\hline 1 & 5.85 & 0.85 & 0.20 & 4.33 & 70.10 & 182.45 & 8.83 & 4.08 & 1.37 & 0.59 & 20.16 & 73.8 \\
\hline
\end{tabular}

Analisis tanah akhir pada lahan sub optimal setelah diaplikasi kompos limbah pelepah kelapa sawit dengan bioaktivator POME

Hasil analisis tanah akhir setelah aplikasi kompos pelepah kelapa sawit dengan bioaktivator mol POME menunjukkan bahwa $\mathrm{pH}$ tanah pada $\mathrm{P} 2$ dan P3 mengalami peningkatan yaitu 5,91 tergolong agak masam dan 6,08 tergolong agak masam.

Tabel 3. Analisis tanah akhir pada lahan sub optimal

\begin{tabular}{|c|c|c|c|c|c|c|c|c|c|c|c|c|}
\hline \multirow[b]{2}{*}{ No } & \multirow[b]{2}{*}{$\mathrm{pH}$} & \multirow{2}{*}{ Corg } & \multirow{2}{*}{$\begin{array}{l}\mathrm{N} \\
\text { total }\end{array}$} & \multirow[b]{2}{*}{$\mathrm{C} / \mathrm{N}$} & $\mathrm{P}$ & $\mathrm{K}$ & \multicolumn{4}{|c|}{ Kation basa (pH 7) } & \multirow{2}{*}{ KTK } & \multirow[b]{2}{*}{$\begin{array}{c}\text { Kej Basa } \\
(\%)\end{array}$} \\
\hline & & & & & \multicolumn{2}{|c|}{$\begin{array}{c}\text { Tersedia } \\
(\mathrm{ppm})\end{array}$} & $\mathrm{Ca}$ & $\mathrm{Mg}$ & $\begin{array}{c}\mathrm{K} \\
\mathrm{e} / 10 \mathrm{C}\end{array}$ & $\mathrm{ga}$ & & \\
\hline P1 & 5,7 & 8,72 & 0,33 & 26,40 & 5,97 & 32,56 & 6,13 & 4,46 & 0,81 & 7,38 & 13,10 & 42,7 \\
\hline $\mathrm{P} 2$ & 5,91 & 11,20 & 0,50 & 22,23 & 10,55 & 40,46 & 10,34 & 3,30 & 1,47 & 9,04 & 16,41 & 49,7 \\
\hline P3 & 6,08 & 19,25 & 0,58 & 33,37 & 11,88 & 45,12 & 12,65 & 3,64 & 2,28 & 1,36 & 18,68 & 37,2 \\
\hline
\end{tabular}

Kandungan basa-basa dapat tukar $\mathrm{Ca}$ pada P1 mengalami penurunan dari tanah awal $8,83 \mathrm{me} / 100 \mathrm{~g}$ yang tergolong sedang menjadi 6,13 me/100g yang tergolong sedang sedangkan pada P2 $(10,34 \mathrm{me} / 100 \mathrm{~g})$ yang tergolong sedang dan P3 (12,65 $\mathrm{me} / 100 \mathrm{~g}$ ) yang tergolong tinggi mengalami peningkatan. Kandungan basa tukar $\mathrm{Mg}$ mengalami peningakatan pada $\mathrm{P} 1$ dari 4,08 me/100g menjadi P1 4,47 me/100g tergolong tinggi dan mengalami penurunan pada P2 dan P3 yaitu 3,30 me/100g dan $3,34 \mathrm{me} / 100 \mathrm{~g}$ tergolong tinggi. 


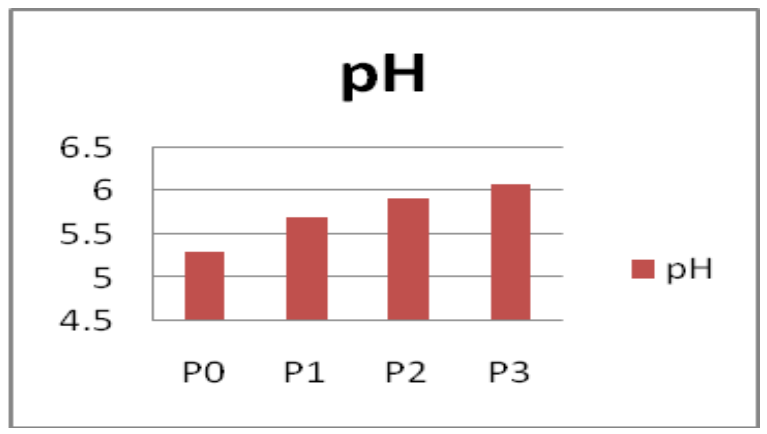

Gambar 1. Grafik pH tanah inkubasi

Kandungan basa dapat tukar K mengalami penurunan dari $1,37 \mathrm{me} / 100 \mathrm{~g}$ dengan status sangat tinggi menjadi $\mathrm{P} 1$ yaitu $0,81 \mathrm{me} / 100 \mathrm{~g}$ tergolong tinggi dan mengalami peningkatan $\mathrm{P} 2$ yaitu 1,47 me/100g dan P3 yaitu 2,28 me/100g tergolong sangat tinggi. Kandungan basa $\mathrm{Na}$ mengalami peningkatan dari $0,59 \mathrm{me} / 100 \mathrm{~g}$ tergolong sedang menjadi P1 yaitu 7,38 me/100g tergolong sangat tinggi, P2 yaitu $9,04 \mathrm{me} / 100 \mathrm{~g}$ tergolong sangat tinggi, dan P3 yaitu 1,36 me/100g tergolong sangat tinggi. Menurut Nazari, Y. A. (2010), kandungan basa yang mengalami penurunan memerlukan tambahan pemupukan yang berimbang untuk meningkatkan kandungan hara tanah.

Nitrogen pada tanah setelah aplikasi kompos pelepah sawit mengalami peningkatan pada semua perlakuan dibandingkan dengan $\mathrm{N}$ pada tanah awal

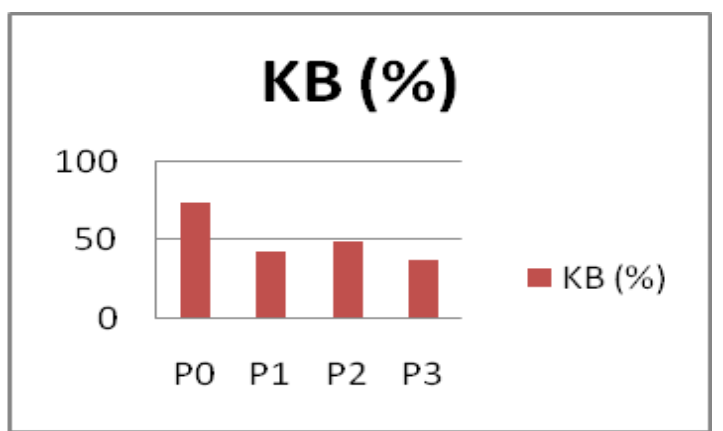

Gambar 2. Grafik Kejenuhan Basa tanah inkubasi

dengan $\mathrm{N}$ tertinggi adalah $0,58 \%$ tergolong tinggi. Unsur Fosfor dan kalium mengalami penurunan pada semua perlakuan dibandingkan dengan tanah awal dengan $\mathrm{P}$ terendah adalah P1 yaitu 5,97 ppm tergolong rendah. Unsur kalium mengalami penurunan dengan $\mathrm{K}$ terendah pada $\mathrm{P} 1$ yaitu $32,56 \mathrm{ppm}$ tergolong sedang. Unsur nitrogen, fosfor dan kalium yang terdapat pada kandungan kompos pelepah sawit berguna untuk mentrasfer energi serta penyusun senyawasenyawa kimia yang mempengaruhi pertumbuhan tanaman (Wahyudi, Herman dan H. Gultom. 2012). Ditambahkan oleh (Raja, 2009 dalam Mulyasari, dkk., 2015) Kompos pelepah kelapa sawit baik kualitasnya karena terbuat dari bahan alami yang dapat meningkatkan kesuburan tanah, sehingga dapat meningkatkan produksi tanaman yang dibudidayakan.

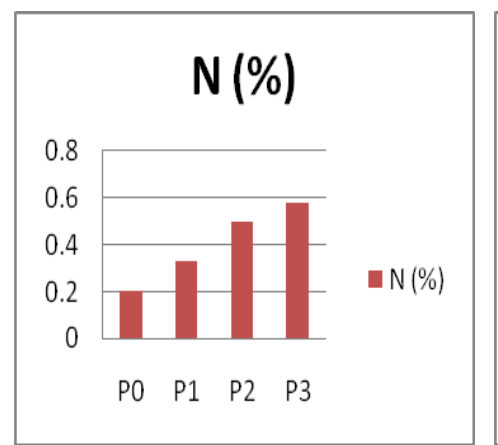

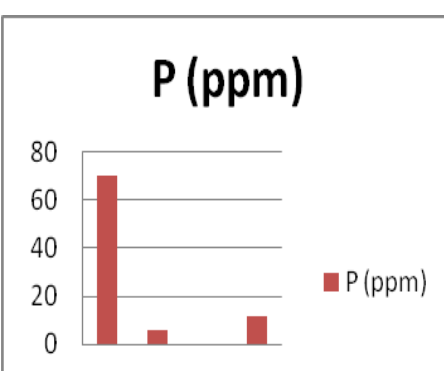

$\begin{array}{llll}\text { P0 } & \text { P1 } & \text { P2 } & \text { P3 }\end{array}$

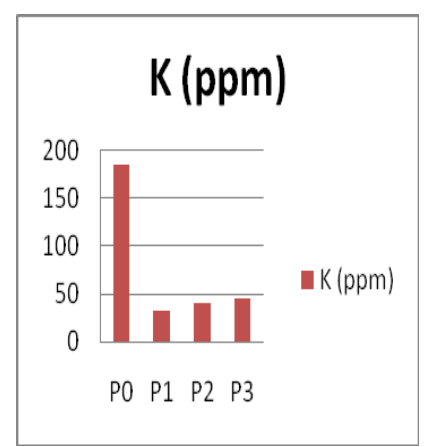

P0 P1 P2 P3

Gambar 3. Grafik Nitrogen, Fosfor da Kalium tanah inkubasi 
Hasil penelitian menunjukkan rasio $\mathrm{C} / \mathrm{N}$ lebih tinggi dibandingkan dengan $\mathrm{C} / \mathrm{N}$ tanah awal. $\mathrm{C} / \mathrm{N}$ tertinggi adalah $\mathrm{P} 3$ yaitu 33,37. $\mathrm{C} / \mathrm{N}$ yang masih tinggi hal ini diduga karena bahan baku kompos berupa pelepah kelapa sawit memiliki $\mathrm{C} / \mathrm{N}$ yang tinggi sehingga membutuhkan waktu yang lebih lama untuk terdekomposisi dengan baik. Hakim (1986) dalam Sundari, 2014, menyatakan bila $\mathrm{C} / \mathrm{N}$ kompos lebih dari 30 maka immobilisasi lebih besar dari mineralisasi, sehingga unsur hara belum tersedia bagi tanaman. Immobilisasi yaitu

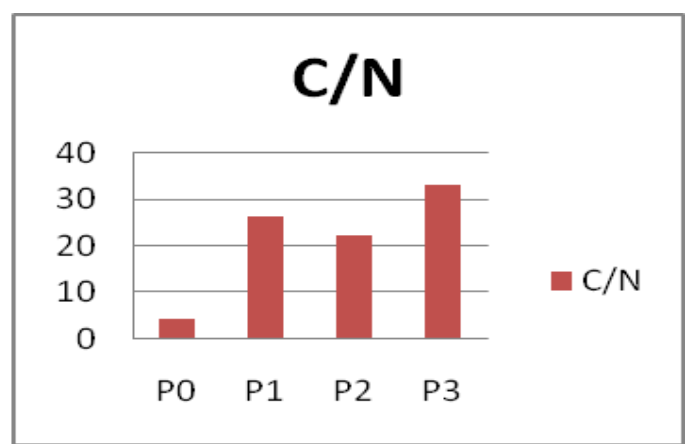

Gambar 5. Grafik $\mathrm{C} / \mathrm{N}$ tanah inkubasi

Kapasitas Tukar kation pada tanah yang diinkubasi dengan kompos pelepah kelapa sawit mengalami penurunan dengan KTK terendah pada P1 yaitu $13,10 \mathrm{me} / 100 \mathrm{~g}$ tergolong rendah. Nilai KTK tanah ini dipengaruh oleh jenis mineral liat, kandungan fraksi liat dan bahan organik. KTK tanah menggambarkan kemampuan tanah dalam menahan/menjerap hara tanaman dalam bentuk kation-kation yang tersedia bagi tanaman, sehingga semakin tinggi nilai KTK semakin banyak hara yang dapat dijerapnya, sedangkan semakin rendah KTK semakin sedikit hara yang dapat dijerap tanah.

\section{KESIMPULAN}

Hasil analisis tanah menunjukkan bahwa $\mathrm{pH}$ tanah mengalami peningkatan dari 5,85 menjadi 6,08, Nitrogen total dari 0,20 menjadi 0,58. Fosfor mengalami suatu proses mikroorganisme pengurai bahan organik masih memanfaatkan unsur hara untuk aktivitas hidupnya. Tanaman memerlukan unsur hara dalam jumlah cukup dan seimbang, jika dalam kompos pelepah kelapa sawit kandungan $\mathrm{C} / \mathrm{N}$ tinggi maka pelepah tersebut belum terdekomposisi dengan sempurna sehingga tanaman sulit untuk menyerap unsur unsur hara yang terkandung di dalamnya. Hartatik dan Widowati (2010) menyatakan bahwa nilai $\mathrm{C} / \mathrm{N}$ yang baik untuk tanaman adalah di bawah

20.

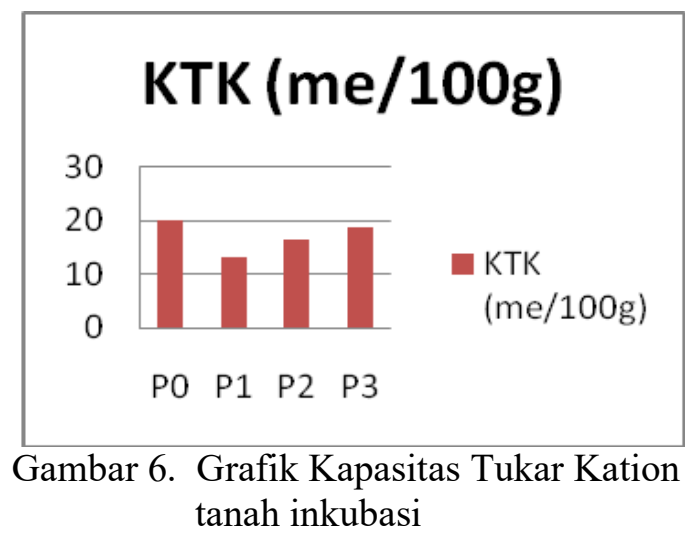

penurunan dari 70,10 menjadi 5,97 (P1), Kalium mengalami penurunan dari 182,45 menjadi 32,56 (P1), Kapasitas Tukar Kation mengalami penurunan dari 20,16 menjadi 13,10 (P1), dan Kejenuhan Basa mengalami penurunan dari 73,8 menjadi 37,2 (P3).

\section{UCAPAN TERIMA KASIH}

Terimakasih kami kepada Universitas Widya Gama Mahakam yang telah memberikan bantuan berupa biaya peneltian. Kami juga menyampaikan terima kasih kepada LPPM dan Fakultas Pertanian Universitas Widya Gama Mahakam yang telah membantu kami dan memfasilitasi dalam kegitan penelitian.

\section{DAFTAR PUSTAKA}

Haji GA. 2013. Komponen limbah asap cair hasil pilorilis limbah padat kelapa 
sawit. Jurnal Rekayasa Kimia dan Lingkungan. 9(3): 109 - 116

Irawan, A. Dariah., dan A. Rachman. Pengembangan dan Diseminasi Inovasi Teknologi Pertanian Mendukung Optimalisasi Pengelolaan Lahan Kering Masam. Jurnal Sumberdaya Lahan Vol. 9 No. 1, Juli 2015; 37-50

Madusari, S., I. Lestari., dan Habiburahman. 2017. Analisis Tingkat Kematangan Kompos Campuran Limbah Padatkelapa Sawit Dengan Penambahan Bioaktivator. Jurnal Citra Widya Edukasi Vol IX no. 3, hal 211-221

Mulyani, A., D. Nursyamsi, dan D.

Harnowo. 2016. Potensi dan Tantangan Pemanfaatan Lahan Suboptimal untuk Tanaman Aneka Kacang dan Umbi. Prosiding Seminar Hasil Penelitian Tanaman Aneka Kacang dan Umbi, hal 16-30

Nazari, Y. A. 2010. Kajian Status Hara Tanah Dan Jaringan Tanaman Kelapa Sawit (Elaeis Guineensis Jacq ) di Kebun Kelapa Sawit Balai Pengkajian dan Pengembangan Pertanian Terpadu Kecamatan Tambang Ulang Pelaihari Kabupaten Tanah Laut. Agroscientiae Volume 17 Nomor 1- April 2010 (1-7)

Sinaga, E., R. Subiantoro., dan Fatahillah. Pengaruh Penggunaan Kompos Pelepah Kelapa Sawit dengan Berbagai Mikroorganisme Lokal (MoL) dan Cara Aplikasinya terhadap Sifat Fisik Tanah dan Produksi Tembakau (Nicotiana tabacum L.). Jurnal AIP Volume 3 No. 1, Mei 2015: 11-20
Siregar, A.F., Dan W. Hartatik. 2010. Aplikasi Pupuk Organik Dalam Meningkatkan Efisiensi Pupuk Anorganik Pada Lahan Sawah . Prosiding Balai Penellitian Tanah

Sismiyanti, Hermansah, dan Yulnafatmawita. 2018. Klasifikasi Beberapa Sumber Bahan Organik Dan Optimalisasi Pemanfaatannya Sebagai Biochar. J. Solum Vol.XV No. 1, Januari 2018: 8-16

Sundari, S. 2014. Pengaruh Pemberian Kompos Pelepah Kelapa Sawit dengan Berbagai Dekomposer terhadap Pertumbuhan dan Hasil Tanaman Pakchoy (Brassica Chinensis L). Jurnal online Fakultas Pertanian Universitas Riau. Februari 2014.

Supriyadi, S. 2008. Kandungan Bahan Organik sebagai Dasar Pengelolaan Tanah di Lahan Kering Madura. Embriyo 5 (2): 176-183

Suryanto, T. 2018. Pemanfaatan Cacahan Limbah Pelepah Kelapa Sawit sebagai Media Tanam terhadap Pertumbuhan Bibit Kelapa Sawit di Pembibitan Awal. Jurnal Citra Widya Edukasi Vol X No. 2 Agustus 2018 ISSN. 2086- 0412

Wahyudi, Herman dan H. Gultom. 2012. Pemberian Kompos Pelepah Sawit Dan Pupuk Npk Mutiara Pada Pertumbuhan Dan Produksi Jagung Manis (Zea Mays Saccharata Sturt). Dinamika Pertanian Volume Xxvii Nomor 3 Desember 2012 (157 - 166)

Mulyasari, I., Herman dan D. I. Roslim. 2015. Pengaruh Dosis Kompos Pelepah Kelapa Sawit Terhadap Hasil Umbi Pada Lima Genotipe Ubi Kayu (Manihot Esculenta Crantz.). 
Jurnal Dinamika Pertanian Volume Xxx Nomor 1 April 2015 (1 - 6)

Rahhutami, R., dan Toto Suryanto. 2018. Pengaruh Pengomposan Pelepah Eks Panen dan Tunasan pada Rorak Berjarak Satu Meter terhadap
Pembungaan Tanaman Kelapa Sawit Menghasilkan Tahun Ke-5. Jurnal Citra Widya Edukasi Vol X No. 2 Agustus 2018 ISSN. 2086-0412 $(125-131)$ 